\title{
The dynamics of insurance prices
}

Henriet, Dominique ; Klimenko, Nataliya ; Rochet, Jean-Charles

\begin{abstract}
We develop a continuous-time general-equilibrium model to rationalise the dynamics of insurance prices in a competitive insurance market with financial frictions. Insurance companies choose underwriting and financing policies to maximise shareholder value. The equilibrium price dynamics are explicit, which allows simple numerical simulations and generates testable implications. In particular, we find that the equilibrium price of insurance is (weakly) predictable and the insurance sector always realises positive expected profits. Moreover, rather than true cycles, insurance prices exhibit asymmetric reversals caused by the reflection of the aggregate capacity process at the dividend and recapitalisation boundaries.
\end{abstract}

DOI: https://doi.org/10.1057/grir.2015.5

Posted at the Zurich Open Repository and Archive, University of Zurich

ZORA URL: https://doi.org/10.5167/uzh-130214

Journal Article

Accepted Version

Originally published at:

Henriet, Dominique; Klimenko, Nataliya; Rochet, Jean-Charles (2016). The dynamics of insurance prices. The Geneva Risk and Insurance Review, 41(1):2-18.

DOI: https://doi.org/10.1057/grir.2015.5 


\title{
The Dynamics of Insurance Prices 추
}

\author{
Dominique Henriet $^{\mathrm{a}}$, Nataliya Klimenko ${ }^{\mathrm{b}}$, Jean-Charles Rochet $^{\mathrm{c}}$ \\ ${ }^{a}$ Ecole Centrale Marseille \& GREQAM-AMSE; 38, rue Frédéric Joliot-Curie 13451 Marseille, France. Email: \\ dominique.henriet@centrale-marseille.fr \\ ${ }^{b}$ University of Zurich; Plattenstrasse 32, 8032 Zurich, Switzerland. Email: nataliya.klimenko@bf.uzh.ch \\ ${ }^{c}$ University of Zurich, SFI and TSE; Plattenstrasse 32, 8032 Zurich, Switzerland. Email: \\ jean-charles.rochet@bf.uzh.ch
}

\begin{abstract}
We develop a continuous-time general-equilibrium model to rationalize the dynamics of insurance prices in a competitive insurance market with financial frictions. Insurance companies choose underwriting and financing policies to maximize shareholder value. The equilibrium price dynamics is explicit, which allows simple numerical simulations and generates testable implications. In particular, we find that the equilibrium price of insurance is (weakly) predictable and the insurance sector always realizes positive expected profits. Moreover, rather than true cycles, insurance prices exhibit asymmetric reversals caused by the reflection of the aggregate capacity process at the dividend and recapitalization boundaries.
\end{abstract}

\section{Introduction}

The phenomenon of "underwriting cycles" appears to be a prominent feature of the insurance industry. Insurance premiums and profits rise (in hard markets phases) and fall (in soft markets phases) with some regularity over time. In soft markets, prices and profits are low and insurance capacity is high, whereas, in hard markets, prices and profits are high, insurance capacity is restricted and policy cancellations or non renewals are frequent. Hard markets can appear very suddenly and they are often referred to as "liability crises" as, for instance, between 1984 and 1986 when premium revenues nearly tripled before slowly decreasing in the next decade.

Meier (2006) studies the existence of such underwriting cycles in property-liability insurance for Switzerland, the USA, Japan and West Germany over a period of 40 years (1957-1997). Using autoregressive models of order 2, she finds cycles for the US, West German and Swiss markets, whereas most specifications for Japan do not reveal cycles. In the same way, Meier and Outreville (2006) show empirical evidence of an underwriting cycle in property-liability insurance for France,

\footnotetext{
${ }^{\text {th }}$ We thank Martin Boyer, George Dionne, Mike Hoy, Jean François Outreville, Peter Zweifel and Michael Powers for helpful comments. Nataliya Klimenko and Jean-Charles Rochet gratefully acknowledge financial support from the Swiss Finance Institute and European Research Council under the European Union's Seventh Framework Program (FP7/2007-2013)/ERC Grant agreement N 249415.
} 
Germany and Switzerland and for the European reinsurance industry between 1982 and 2001. However, a more recent study by Boyer, Jacquier and Van Norden (2012) casts doubt on the reality of $\operatorname{AR}(2)$ cycles. Their argument is that standard estimation techniques overstate the likelihood of having a cycle because of the non linearity of the link between $\operatorname{AR}(2)$ parameters and the value of the period. They conclude that the observed underwriting fluctuations cannot be considered as truly cyclical.

From a theoretical perspective, it is hard to explain cycles by the conventional view according to which insurance premiums should be informationally efficient predictors of the present value of policy claims and expenses. For such arbitrage oriented theories, underwriting cycles come largely from institutional lags and reporting practices. In some sense, they are artefacts essentially due to accounting rules, informational delays or regulatory rigidities (see e.g., Cummins and Outreville (1987), Lamm-Tennant and Weiss (1997) or Chen, Wong and Lee (1999)).

By contrast, capacity constraint theories suggest that real frictions on capital markets can be the cause of underwriting cycles by making the industry's capacity temporarily dependent on short-term profits and losses. According to this approach, a cycle begins when insurers dramatically reduce capacity after large losses that have depleted their reserves. After some time, reserves are restored and capacity increases again. But the increase in underwriting capacity increases competition, which, in turn, drives premiums down. When insurers incur a reduction in capital due to unexpected losses, they are reluctant to issue new equity due to high issuance costs. This implies that shocks to insurers' capital affect the price and quantity of insurance supplied in the short run. In such a context, prices are not really periodic but only reflect past losses. From that point of view, a cycle is a time lapse to recover capacity.

In this paper we propose a fully fledged dynamic model that reconciles arbitrage oriented and capacity constraint theories. In our model, insurers are value-maximizers and competitive. However, they face a finance market with frictions, in that issuing new equity is costly. ${ }^{1}$ The industry capacity (aggregate liquid reserves) determines the dynamics of dividends, recapitalizations and premiums. Insurance companies distribute dividends when the sector capacity is high and the expected profits are low. Symmetrically, recapitalizations take place when capacity becomes too small. The reflection property of the capacity process at two boundaries causes oscillations that lead to a quasi-cyclical pattern. The equilibrium price of insurance is a decreasing function of the industry capacity and its maximum level is increasing with the magnitude of the financial frictions.

An interesting prediction generated by our model is that underwriting "cycles" will in general be asymmetric. We measure the average duration of the soft market phase by the expected time it takes for the price of insurance to reach its minimum level while starting at its maximum level. In

\footnotetext{
${ }^{1}$ The notion that external equity financing is more costly than financing via retained earnings is discussed e.g. in Winter (1994). On the empirical side, Gron and Lucas (1998) find evidence of the important costs of raising external capital for the property-casualty insurers.
} 
a similar fashion, the average duration of the hard market phase is approximated by the expected time it takes for the price of insurance to recover from its minimum level up to its maximum level. Consistent with empirical evidence reported in Figure 1, our numerical analysis shows that the soft market phase lasts longer (in expectation) than the hard market phase. Moreover, this difference turns out to be more pronounced when the elasticity of the demand for insurance is high.

Figure 1: Insurance price index

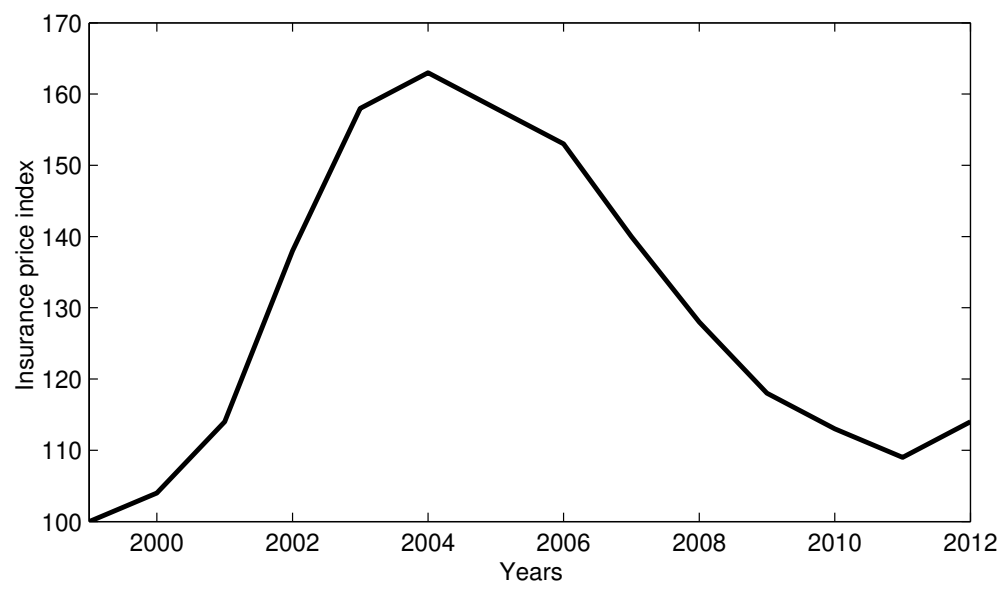

Notes: this figure reports the pattern of the insurance price index (data from The Council of Insurance Agents and Brokers 2013, base 100:1999), showing evidence that the "soft market" phase (declining prices) lasts longer than the "hard market" phase (rising prices).

Our paper is related to the earlier literature that attempts to link the emergence of cycles to changes in insurers' net worth. Stewart (1984) and Bloom (1987) have developed two simple models along this line. They rely on a partial equilibrium approach where the shifts of insurance supply curves explain the underwriting cycle. The position of the supply curve is affected by insurers' net worth and the form of insurer expectations explains the timing and length of the high-price phase.

Cagle and Harrington (1995) propose a model of insurance supply with capacity constraints and endogenous default risk. If industry demand is inelastic with respect to price and capital, the price will increase following a negative shock to capital. Choi, Hardigree and Thistle (2002) perform an empirical comparison of six alternative models of insurance pricing using data between 1935 and 1997. They find that the capacity constraint model is consistent with data, both in the long and short term. Gron (1994) also provides empirical support for the primary predictions of capacity constraint theories of property-casualty insurance cycles.

The closest related paper is Winter (1994) who develops a discrete time model similar to ours. Namely, in Winter (1994) insurers accumulate equity capital so as to rule out default and to be able to meet policyholders' claims. This feature implies an upward-sloping short-run supply curve whose position is determined by the level of capital. On top of this, a cost differential between internal and external sources of capital prevents financial capital from quickly adjusting. The insured individual 
risk is the loss of one dollar with a probability that is common to all insurees but which is itself random. As in our model, the state variable is the total net wealth of the insurance companies and the (rational expectation) equilibrium is characterized by the joint dynamics of insurance prices and market-to-book (Tobin's q) ratio. However, in contrast to our model, the recursive characterization of the equilibrium dynamics in Winter (1994) does not allow explicit solutions. Winter shows, through simulation methods, that the equilibrium price is larger than the expected loss and is negatively correlated with capacity.

Our model can be seen as a continuous time version of Winter (1994). While generating the main predictions consistent with those obtained in discrete time, it allows the explicit characterization of equilibrium dynamics. We illustrate the advantage of using the continuous-time approach by analysing the cyclical properties of price fluctuations.

The rest of the paper is organized as follows. Section 2 presents the model. Section 3 characterizes the competitive equilibrium. Section 4 studies the dynamics of insurance prices. Section 5 concludes.

\section{The Model}

We consider a competitive insurance market that consists of a continuum of insurance companies offering insurance to individuals who face perfectly correlated risks ${ }^{2}$ (such as weather risks). All agents discount the future at a constant rate $r$. The cumulative loss $L_{t}$ incurred by each individual up to date $t$ is such that

$$
d L_{t}=\ell d t+\sigma_{0} d B_{t}
$$

where $\ell$ denotes expected losses per unit of time, $\sigma_{0}$ is an exposure parameter and $B_{t}$ is a standard Brownian motion defined on the probability space $(\Omega, \mathbb{F}, \mathrm{P})$ that generates the filtration $\mathbb{F}=\left\{\mathcal{F}_{t}, t \geq\right.$ $0\}$. We assume that $B_{t}$ is the same for all individuals (perfect correlation between risks).

Insurance contracts are short-term and the market price of insurance per unit of time is

$$
\pi_{t}=\ell+\sigma_{0} p_{t}
$$

where $p_{t}$ is a (rescaled) loading factor. For simplicity, throughout the paper we refer to $p_{t}$ as to the price of insurance. The demand for insurance is exogenously given by a function $D(p)$, such that $D^{\prime}()<$.0 .

Since insurance contracts have an infinitesimal length, insurers have no long-term liabilities. Thus, the balance sheet of each insurance company has only one item on each side: equity $e_{t}$ on the liability side and liquid reserves on the asset side with $e_{t}=m_{t}$. Therefore, $m_{t}$ ( $M_{t}$ on aggregate) can be viewed simultaneously as the volume of individual (respectively, aggregate) reserves or as

\footnotetext{
${ }^{2}$ The idiosyncratic part of individual risk is neglected, since it can be eliminated by diversification.
} 
the book value of equity for an insurance company (respectively, the entire insurance industry). In an infinitesimal period $(t, t+d t)$, an individual insurer operating at a scale $x_{t}$ generates earnings $x_{t}\left(\pi_{t} d t-d L_{t}\right)$ that can be distributed as dividends or can be retained in reserves. Moreover, insurance companies can increase the level of reserves by raising new equity, which entails a proportional $\operatorname{cost} \gamma \cdot{ }^{3}$

The dynamics of reserves $m_{t}$ of an insurance company operating at scale $x_{t}$ at time $t$ is given $\mathrm{by}^{4}$

$$
d m_{t}=\sigma_{0} x_{t}\left(p_{t} d t-d B_{t}\right)+d i_{t}-d \delta_{t}
$$

where $d \delta_{t} \geq 0$ and $d i_{t} \geq 0$ denote, respectively, the changes in the cumulative dividend and recapitalization amounts. In fact, our model can be viewed as a general equilibrium version of the classical ruin theory model (in its Brownian version, as in Gerber-Shiu (2004)), where reserves' dynamics is given by

$$
d m_{t}=\mu d t-\sigma_{0} d B_{t}-d \delta_{t}
$$

The main difference, however, pertains to the fact that, in our setting, prices and quantities are endogenous, and insurance companies have the possibility to recapitalize.

Provided that, at equilibrium, the supply of insurance contracts equals the demand, the dynamics of aggregate reserves (capacity) of the entire insurance sector satisfy

$$
d M_{t}=\sigma_{0} D\left(p_{t}\right)\left(p_{t} d t-d B_{t}\right)+d I_{t}-d \Delta_{t}
$$

where $d \Delta_{t} \geq 0$ and $d I_{t} \geq 0$ denote, respectively, the changes in the aggregate cumulative dividend and recapitalization amounts.

In our model, we focus on a Markovian stationary equilibrium, in which the insurance price is a deterministic function of the aggregate level of reserves in the insurance sector, i.e., $p_{t}=p\left(M_{t}\right)$. To formally define the equilibrium, let $\mathbb{J}=[0,1]$ denote the set of insurance companies, each of which is indexed by $j \in \mathbb{J}$.

Definition 1. A stationary Markovian competitive equilibrium consists of an aggregate reserves process $M_{t}$, a price of insurance $p(M)$ and insurance supply functions $x^{j}(M), j \in \mathbb{J}$, that are compatible with insurer's profit maximization and the market clearing condition $\int_{\mathbb{J}} x^{j}(M) d j=D[p(M)]$.

In the following section we establish the existence of a unique stationary Markovian equilibrium and study its main properties.

\footnotetext{
${ }^{3}$ According to Gron and Lucas (1998), for example, the direct costs of equity issues range from 1 to $5 \%$ of the value issued.

${ }^{4}$ We assume that reserves earn no interest.
} 


\section{Equilibrium}

Each insurance company takes the price of insurance $p\left(M_{t}\right)$ and the dynamics of $M_{t}$ as given and chooses the scale of operation $x_{t} \geq 0$, dividend $d \delta_{t} \geq 0$ and recapitalization $d i_{t} \geq 0$ policies so as to maximize shareholder value:

$$
v(m, M)=\max _{x_{t} \geq 0, d \delta_{t} \geq 0, d i_{t} \geq 0} \mathbb{E}\left[\int_{0}^{+\infty} e^{-r t}\left\{d \delta_{t}-(1+\gamma) d i_{t}\right\}\right]
$$

where $m_{t}$ follows (1) and $M_{t}$ follows (2).

Note that the objective function and the state equation (1) are homogeneous in $(m, x, d \delta, d i)$ implying that the value function is linear in the individual level of reserves, i.e.,

$$
v(m, M)=m u(M)
$$

where $u(M)$ is the market-to-book value of the insurance company, which is the same for the entire insurance sector. ${ }^{5}$

Given the above property of the value function, one can easily show that the Bellman equation corresponding to shareholder maximization can be written as follows:

$$
\begin{aligned}
r u(M)=\max _{x \geq 0, d \delta \geq 0, d i \geq 0} \quad[ & x \sigma_{0}\left\{p(M) u(M)+\sigma_{0} D[p(M)] u^{\prime}(M)\right\} \\
& +\sigma_{0} D(p) p(M) u^{\prime}(M)+\frac{\sigma_{0}^{2} D^{2}[p(M)]}{2} u^{\prime \prime}(M) \\
& \left.+\frac{d \delta}{m}\{1-u(M)\}-\frac{d i}{m}\{1+\gamma-u(M)\}\right],
\end{aligned}
$$

where the term in the left-hand side is the expected return from holding one unit of equity in the insurance company, the first term in the right-hand side (in curly brackets) captures the impact of individual risk exposure, the second and the third terms in the right-hand side reflect the impact caused by the changes in the aggregate capacity of the insurance sector and the last two terms capture, respectively, the impact of the payout and recapitalization policies.

Consider first the optimal dividend and recapitalization policies. Maximizing with respect to $d \delta \geq 0$ and $d i \geq 0$ implies strong conditions on $u($.$) :$

$$
u(M) \geq 1
$$

\footnotetext{
${ }^{5}$ Note that $u(M)$ can be interpreted as the market value of one dollar of net worth (book value) in the insurance sector when total capacity is $M$. It represents the insurance analogue of Tobin's q ratio, as in Winter (1994).
} 
with $d \delta>0$ only when $u(M)=1$, and

$$
u(M) \leq 1+\gamma
$$

with $d i>0$ only when $u(M)=1+\gamma$.

As we show below, the market-to-book ratio of the insurance sector is a decreasing function of its aggregate capacity, i.e., $u^{\prime}(M)<0$. This implies that aggregate capacity $M$ varies between two (reflecting) boundaries and, as in many diffusion models dealing with the optimal liquidity management, ${ }^{6}$ the optimal dividend and recapitalization policies in our model are of a so-called barrier type. In particular, dividends are distributed when the insurance sector is sufficiently capitalized so that aggregate reserves reach a critical level $\bar{M}$ such that the market-to-book value of the insurer's equity falls to 1, i.e.,

$$
u(\bar{M})=1 .
$$

By contrast, recapitalizations take place when the insurance sector is undercapitalized and reserves fall to a critical level $\underline{M}<\bar{M}$ such that the marginal value of holding one share in the insurance company equals the marginal cost of issuing a new share, i.e.,

$$
u(\underline{M})=1+\gamma
$$

We turn now to the optimal choice of the scale of operation of an insurer. Maximization with respect to $x_{t}$ implies that an interior solution exists if and only if the market-to-book value $u(M)$ and the price $p(M)$ satisfy:

$$
p(M)=-\frac{u^{\prime}(M)}{u(M)} \sigma_{0} D[p(M)]
$$

Under the above equality, the term in $x$ vanishes from the Bellman equation (3) and, on the interval $(\underline{M}, \bar{M})$ where aggregate capacity evolves solely due to retained earnings, the latter transforms to

$$
r u(M)=\sigma_{0} D(p) p(M) u^{\prime}(M)+\frac{\sigma_{0}^{2} D^{2}[p(M)]}{2} u^{\prime \prime}(M), \quad M \in(\underline{M}, \bar{M}) .
$$

Dividing the above equation by $u(M)$ and using Equation (6) to replace the term $\frac{u^{\prime}(M)}{u(M)}$, one obtains:

$$
r+p^{2}(M)=\frac{\sigma_{0}^{2} D^{2}[p(M)]}{2} \frac{u^{\prime \prime}(M)}{u(M)} .
$$

As long as the price of insurance $p(M)$ satisfies Equations $(6)$ - (7), the shareholders of an insurance company are indifferent with respect to their scale of operation. The size of the insurance

\footnotetext{
${ }^{6}$ See e.g., Jeanblanc and Shiryaev (1995), Rochet and Villeneuve (2011), Bolton, Chen and Wang (2011). In the context of actuarial models, various applications of the optimal liquidity management are discussed in Schmidli (2008).
} 
sector will therefore be entirely determined by the demand side.

Fundamentally, Equations (6) - (7) stem from the absence of arbitrage opportunities and perfect competition in the insurance market. To see this, we resort to the non-arbitrage arguments. Consider the total market value (total capitalization) of the insurance sector at time $t$ :

$$
W_{t} \equiv u\left(M_{t}\right) M_{t}
$$

The arbitrage free condition implies

$$
\mathbb{E}\left[d W_{t}\right]=r W_{t} d t
$$

or, equivalently,

$$
\mathbb{E}\left[u\left(M_{t}+d M_{t}\right) M_{t}\right]+\mathbb{E}\left[u\left(M_{t}+d M_{t}\right) d M_{t}\right]-u\left(M_{t}\right) M_{t}=r u\left(M_{t}\right) M_{t} d t .
$$

Given the law of motion of $M_{t}$, the second term in the above equation can be rewritten as follows:

$$
\mathbb{E}\left[u\left(M_{t}+d M_{t}\right) d M_{t}\right]=\left\{u\left(M_{t}\right) p\left(M_{t}\right) d t-\mathbb{E}\left[u\left(M_{t}+d M_{t}\right) d B_{t}\right]\right\} \sigma_{0} D\left[p\left(M_{t}\right)\right],
$$

where the term in the right-hand side is the expected market value of the profit margin generated by insurance activity. Perfect competition on the insurance market implies that this market value is zero, i.e.,

$$
u\left(M_{t}\right) p\left(M_{t}\right) d t=\mathbb{E}\left[u\left(M_{t}+d M_{t}\right) d B_{t}\right]
$$

Computing the expectation in the right-hand side of (9) using the fact that $\mathbb{E}\left[d M_{t} d B_{t}\right]=$ $-\sigma_{0} D[p(M)] d t$ yields Equation (6). Moreover, combining (9) and (8) leads to:

$$
\mathbb{E}\left[d u\left(M_{t}\right)\right]=r u\left(M_{t}\right) d t
$$

which, by using Itô's lemma and Equation (6), can be rewritten as (7).

To determine the equilibrium insurance price, note that Equation (6) can be rewritten as follows:

$$
\frac{u^{\prime}(M)}{u(M)}=-\frac{p(M)}{\sigma_{0} D[p(M)]}
$$

Differentiating the above equation yields:

$$
\frac{u^{\prime \prime}(M)}{u(M)}-\left[\frac{u^{\prime}(M)}{u(M)}\right]^{2}=-p^{\prime}(M)\left[\frac{1}{\sigma_{0} D[p(M)]}-\frac{p(M) D^{\prime}[p(M)]}{\sigma_{0} D^{2}[p(M)]}\right] .
$$


Inserting $\frac{u^{\prime \prime}(M)}{u(M)}$ from the above equation into (7) yields

$$
2\left(r+p^{2}(M)\right)=p^{2}(M)-\sigma_{0} p^{\prime}(M)\left(D[p(M)]-p D^{\prime}[p(M)]\right)
$$

which ultimately leads to a first-order differential equation determining the equilibrium price:

$$
p^{\prime}(M)=-\frac{1}{\sigma_{0}} \frac{2 r+p^{2}(M)}{D[p(M)]-p(M) D^{\prime}[p(M)]} .
$$

Given that $D^{\prime}()<$.0 , it is immediate to see from the above equation that the price of insurance is inversely related to the aggregate capacity of the insurance sector. Moreover, applying Itô's lemma to $p_{t}=p\left(M_{t}\right)$, we can obtain an explicit characterization of the insurance price process. Indeed,

$$
d p_{t}=\underbrace{\sigma_{0} D\left[p\left(M_{t}\right)\right]\left(p_{t}\left(M_{t}\right) p^{\prime}\left(M_{t}\right)+\frac{\sigma_{0} D\left[p\left(M_{t}\right)\right]}{2} p^{\prime \prime}\left(M_{t}\right)\right)}_{\mu\left(p_{t}\right)} d t \underbrace{-\sigma_{0} D\left[p\left(M_{t}\right)\right] p^{\prime}\left(M_{t}\right)}_{\sigma\left(p_{t}\right)} d B_{t} .
$$

A simple computation immediately yields the expression of the insurance price volatility:

$$
\sigma(p)=\frac{2 r+p^{2}}{1+\varepsilon_{1}(p)}
$$

where $\varepsilon_{1}(p)$ is the elasticity of the demand for insurance:

$$
\varepsilon_{1}(p) \equiv-\frac{p D^{\prime}(p)}{D(p)}
$$

Therefore, Equation (10) can be rewritten as follows:

$$
p^{\prime}(M)=-\frac{\sigma[p(M)]}{\sigma_{0} D[p(M)]},
$$

which demonstrates that the changes in the equilibrium insurance price are mainly driven by the endogenous volatility.

Furthermore, simplifying the expression of the drift of the insurance premium yields:

$$
\mu(p)=\sigma(p)\left[\frac{\left(2 r+p^{2}\right) \varepsilon_{1}(p) \varepsilon_{2}(p)}{2 p\left(1+\varepsilon_{1}(p)\right)^{2}}-\frac{p \varepsilon_{1}(p)}{1+\varepsilon_{1}(p)}\right]
$$

where

$$
\varepsilon_{2}(p) \equiv-\frac{p D^{\prime \prime}(p)}{D^{\prime}(p)}
$$

To complete the characterization of the competitive equilibrium, let $V(M) \equiv M u(M)$ denote the market value of the entire insurance industry. The absence of arbitrage opportunities at the 
(reflecting) boundaries $\underline{M}$ and $\bar{M}$ implies that

$$
V^{\prime}(\bar{M}) \equiv u(\bar{M})+\bar{M} u^{\prime}(\bar{M})=1
$$

and

$$
V^{\prime}(\underline{M}) \equiv u(\underline{M})+\underline{M} u^{\prime}(\underline{M})=1+\gamma .
$$

Together with Equations (4) and (5), this respectively implies two conditions: $u^{\prime}(\bar{M})=0$ and $\underline{M}=0$. Inserting $u^{\prime}(\bar{M})=0$ into Equation (6), it is easy to see that, when the insurance industry operates at the maximum level of reserves, the loading factor vanishes, i.e., $\underline{p} \equiv p(\bar{M})=0$. Since $p^{\prime}(M)<0$, this implies that $p(M)>0^{7}$ for all $M>0$ and, therefore, $u^{\prime}(M)<0$ as was conjectured before. The following proposition summarizes our results.

Proposition 1. There exists a unique stationary Markovian equilibrium, in which aggregate reserves in the insurance sector evolve according to:

$$
d M_{t}=\sigma_{0} D\left[p\left(M_{t}\right)\right]\left(p\left(M_{t}\right) d t-d B_{t}\right), \quad M_{t} \in(0, \bar{M}) .
$$

The insurance price function $p(M)$ satisfies the differential equation

$$
p^{\prime}(M)=-\frac{\sigma[p(M)]}{\sigma_{0} D[p(M)]},
$$

with the boundary condition $p(0)=\bar{p}$, where $\bar{p}$ solves

$$
\int_{0}^{\bar{p}} \frac{p}{\sigma(p)} d p=\ln (1+\gamma)
$$

Proof of Proposition 1: We have already established that any equilibrium price function $p(M)$ must satisfy the first-order differential Equation (13). Uniqueness of the equilibrium will result from the Cauchy-Lipschitz theorem, once the boundary value $p(0)=\bar{p}$ is determined. Once $p(M)$ is known, function $u(M)$ can be computed by solving

$$
\frac{u^{\prime}(M)}{u(M)}=-\frac{p(M)}{\sigma_{0} D[p(M)]}
$$

which yields

$$
u(M)=u(\bar{M}) \exp \left(\int_{M}^{\bar{M}} \frac{p(s)}{\sigma_{0} D[p(s)]} d s\right)
$$

\footnotetext{
${ }^{7}$ This property of our model implies that insurance companies always generate non-negative expected profits. In practice, however, loading factors can be negative, as insurers can hedge their losses via complementary financial market activities.
} 
Since $u(\bar{M})=1$ and $u(0)=1+\gamma$, this implies

$$
\int_{0}^{\bar{M}} \frac{p(s)}{\sigma_{0} D[p(s)]} d s=\ln (1+\gamma) .
$$

Finally, changing the variable of integration in the above equation to $p(s)=p$ yields $(17)$. Q.E.D.

Note that, in the competitive equilibrium, insurance companies recapitalize only when running out of reserves. At the same time, the target level of aggregate reserves in the insurance industry can easily be computed according to

$$
\bar{M}=\int_{0}^{\bar{p}} \frac{\sigma_{0} D(p)}{\sigma(p)} d p .
$$

It is immediate to see from Equations (17) and (18) that both the maximum level of insurance price $\bar{p}$ and the target level of reserves $\bar{M}$ increase with the financing cost $\gamma$. This feature of the competitive equilibrium emerging in our model suggests that the magnitude of underwriting "cycles" observed in practice might be intrinsically related to the magnitude of financial frictions faced by insurance companies.

\section{Dynamics of insurance prices}

In this section we study the dynamics of the equilibrium price of insurance as predicted by our model. For convenience, we use the following specification of the demand for insurance:

$$
D(p)=(\alpha-p)^{\beta}
$$

where $\beta>0$ and $\alpha>0$. Parameter $\alpha$ can be interpreted as the price above which demand for insurance vanishes. Both $\alpha$ and $\beta$ affect the elasticity of demand for insurance. More precisely, we have

$$
\varepsilon_{1}(p)=\frac{\beta p}{\alpha-p}, \quad \varepsilon_{2}(p)=\frac{(\beta-1) p}{\alpha-p} .
$$

Inserting $\varepsilon_{1}(p)$ and $\varepsilon_{2}(p)$ into the general formulas of $\sigma(p)$ and $\mu(p)$, we obtain two simple expressions that will be further used to illustrate the dynamics of the equilibrium price:

$$
\begin{gathered}
\sigma(p)=\frac{(\alpha-p)\left(p^{2}+2 r\right)}{p(\alpha+(\beta-1) p)} \\
\mu(p)=\sigma(p) \beta p\left[\frac{(\beta-1)\left(2 r-p^{2}\right)-2 \alpha p}{2(\alpha+(\beta-1) p)^{2}}\right] .
\end{gathered}
$$




\subsection{Mean reversion}

It is easy to see from Expression (20) that the sign of the insurance price drift is determined by the sign of the polynomial

$$
h(p) \equiv(\beta-1)\left(2 r-p^{2}\right)-2 \alpha p .
$$

It can be shown that, for $\alpha>\sqrt{2} r$ and $\beta>1$, the equation $h(p)=0$ has a unique root $p^{*}$ on the interval $(0, \alpha)$ such that $\mu(p)>0$ on $\left(0, p^{*}\right)$ and $\mu(p)<0$ on $\left(p^{*}, \alpha\right)$. This implies that the price process $p_{t}$ exhibits mean reversion. However, it important to note that this mean reversion property manifests itself only when the financing cost $\gamma$ is sufficiently high. Indeed, recall that the maximum level of insurance price, $\bar{p}$, is an increasing function of $\gamma$ with $\bar{p}=0$ when $\gamma=0$. Thus, when $\gamma$ is low, $p^{*}>\bar{p}$ and $\mu(p)>0$ for all $p \in(0, \bar{p})$.

Moreover, this mean-reversion property is not very strong. Indeed, for most parameter combinations, $|\mu(p)|$ turns out to be very small as compared to $\sigma(p)$ (see the left and the central panels in Figure 3). The main feature of the dynamics of the price process $p_{t}$ is its reflection at the boundaries of the interval $(0, \bar{p})$, which induces what we call price reversals.

\subsection{Price reversals}

The reflection property of the aggregate reserve process in our model induces reversals of the price of insurance. Empirical work has shown that the insurance market alternates "soft market" phases characterized by falling premiums together with an expansion of insurers' capacities and "hard market" phases characterized by rising premiums together with a contraction of insurers' capacities. $^{8}$

Our model can be used to compute the expected duration of each phase of the underwriting cycle by using the dynamics of the price of insurance defined in Equation (11). In particular, the expected duration of the soft market phase (i.e., falling insurance prices) can be measured as the expected time needed for the process $p_{t}$ to reach 0 while starting from the state $\bar{p}$. In a similar fashion, the expected duration of the hard market phase (i.e., rising insurance prices) can be measured by the expected time that the process $p_{t}$ needs to reach the state $\bar{p}$ while starting from 0 .

To formalize this, let $T_{s}(p)$ denote the expected time that the price process $p_{t}$ takes in order to reach any state $p \leq \bar{p}$ starting from the state $\bar{p}$ and let $T_{h}(p)$ be the expected time it takes to reach the state $\bar{p}$ starting from any $p \leq \bar{p}$. We will refer to $\bar{T}_{s} \equiv T_{s}(0)$ as the average duration of the soft market phase and to $\bar{T}_{h} \equiv T_{h}(0)$ as the average duration of the hard market phase.

Proposition 2. The average duration of the soft market phase can be computed as $\bar{T}_{s} \equiv T_{s}(0)$, where function $T_{s}(p)$ satisfies

$$
1-\mu(p) T_{s}^{\prime}(p)-\frac{\sigma^{2}(p)}{2} T_{s}^{\prime \prime}(p)=0
$$

\footnotetext{
${ }^{8} \mathrm{~A}$ detailed review of the literature on underwriting cycles can be found in Harrington et al.(2013).
} 
with the boundary conditions $T_{s}(\bar{p})=0$ and $T_{s}^{\prime}(\bar{p})=0$.

The average duration of the hard market phase can be computed as $\bar{T}_{h} \equiv T_{h}(0)$, where function $T_{h}(p)$ satisfies

$$
1+\mu(p) T_{h}^{\prime}(p)+\frac{\sigma^{2}(p)}{2} T_{h}^{\prime \prime}(p)=0
$$

with the boundary conditions $T_{h}(\bar{p})=0$ and $T_{h}^{\prime}(0)=0$.

Proof of Proposition 2: To derive the ODE (21), let $g_{p_{0}}(p)$ denote the expected time that is needed to reach some state $p_{0}$ starting from any $p \geq p_{0}$, where $p_{0} \leq p \leq \bar{p}$. Then, $T_{s}\left(p_{0}\right)=$ $T_{s}(p)+g_{p_{0}}(p)$ and thus $T_{s}(p)=T_{s}\left(p_{0}\right)-g_{p_{0}}(p)$. By the Feynman-Kac theorem, ${ }^{9}$ function $g_{p_{0}}(p)$ must satisfy the ODE:

$$
1+\mu(p) g_{p_{0}}^{\prime}(p)+\frac{\sigma^{2}(p)}{2} g_{p_{0}}^{\prime \prime}(p)=0
$$

Using the fact that $g_{p_{0}}^{\prime}(p)=-T_{s}^{\prime}(p)$ and $g_{p_{0}}^{\prime \prime}(p)=-T_{s}^{\prime \prime}(p)$, one obtains ODE (21). The boundary condition $T_{s}(\bar{p})=0$ reflects the fact that at $\bar{p}$ the time to reach $\bar{p}$ is zero, whereas the boundary condition $T_{s}^{\prime}(\bar{p})=0$ emerges due to the reflection of the price of insurance at $\bar{p}$. The same arguments apply to establish the boundary conditions for the function $T_{h}(p)$ to which the Feynman-Kac theorem applies directly. Q.E.D.

The left-hand side and the central panels of Figure 2 report, respectively, the values of $\bar{T}_{s}$ and $\bar{T}_{h}$ as functions of parameter $\alpha$ for two different levels of $\beta$. The right-hand side panel of Figure 2 reports the corresponding difference $\bar{T}_{s}-\bar{T}_{h}$.

These numerical results clearly show that, for parameter combinations implying a higher elasticity of demand for insurance (i.e., higher $\beta$ and lower $\alpha$ ), the "cycles" emerging in our model are asymmetric, and the soft market phase tends to be substantially longer than the hard market phase. A potential explanation for this feature rests on the observation that, in the setting with an elastic demand for insurance, the endogenous volatility is a monotonically decreasing function of $p$. Since the endogenous volatility is lower in the states with higher price of insurance, the system actually needs more time to make a downward move rather than to make an upward move. For the parameter combinations implying a highly inelastic demand for insurance, the endogenous volatility pattern is $U$-shaped and the difference between the average durations of the soft and hard market phases is almost negligible.

\subsection{Long-run behavior}

To study the dynamics of the price of insurance in the long run, we look at its ergodic density function that reflects the proportion of time that the price process spends in each feasible state in the long run. Given the price dynamics in (11), the latter can be computed by solving the forward

\footnotetext{
${ }^{9}$ See e.g., Shreve (2004), Chapter 6.4.
} 
Figure 2: Average duration of soft and hard markets
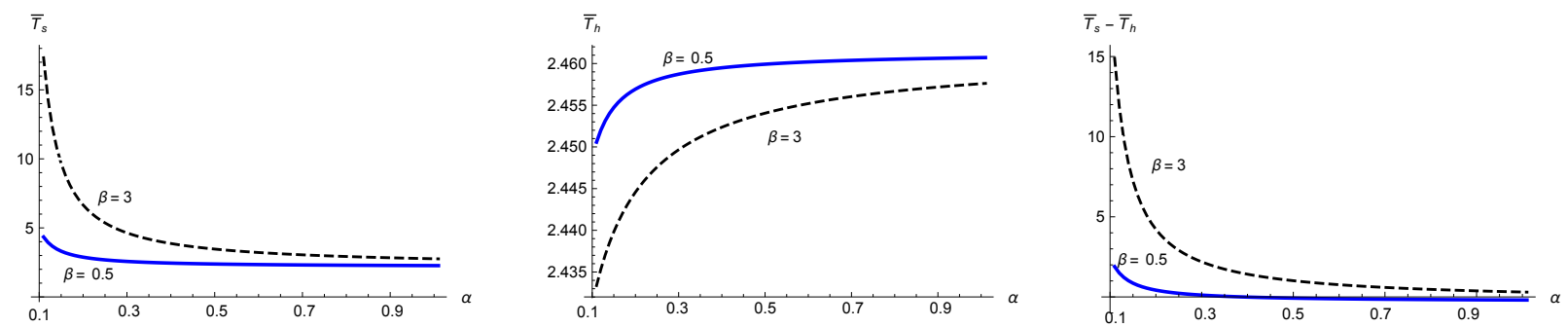

Notes: this figure reports the average duration of the soft market phase $\bar{T}_{s}$ (the left panel), the average duration of the hard market phase $\bar{T}_{h}$ (the central panel) and their difference $\bar{T}_{s}-\bar{T}_{h}$ (the right panel) as functions of parameter $\alpha$. Solid lines correspond to $\beta=0.5$ and dashed lines refer to $\beta=3$. Parameter combinations with higher (lower) $\beta$ and lower (higher) $\alpha$ correspond to the elastic (inelastic) demand for insurance. Other parameter values are set as follows: $r=0.04, \sigma_{0}=0.05$, $\gamma=0.1$.

Kolmogorov equation, ${ }^{10}$ which ultimately yields:

$$
f(p)=\frac{C_{0}}{\sigma^{2}(p)} \exp \left(\int_{0}^{p} \frac{2 \mu(s)}{\sigma^{2}(s)} d s\right)
$$

where the constant $C_{0}$ is such that $\int_{0}^{\bar{p}} f(p) d p=1$.

The right panel in Figure 3 depicts the typical pattern of this ergodic density showing that the latter tends to be concentrated in the states with the low endogenous volatility. This property of the ergodic density function shows that the negative shocks incurred by insurers may generate persistence, so that the system can spend quite some time in the states with high insurance prices and low insurance capacity. As in the recent equilibrium models with financial frictions (see e.g., Brunnermeier and Sannikov (2014), Klimenko, Pfeil and Rochet (2015)), persistence emerges as a natural consequence of the capacity adjustments implemented by insurance companies following profit and losses. In particular, unexpected losses are followed by a reduced scale of operations, implying that it may take a long time for insurers to restore their capacity.

Figure 3: Drift, volatility and ergodic density of the insurance price
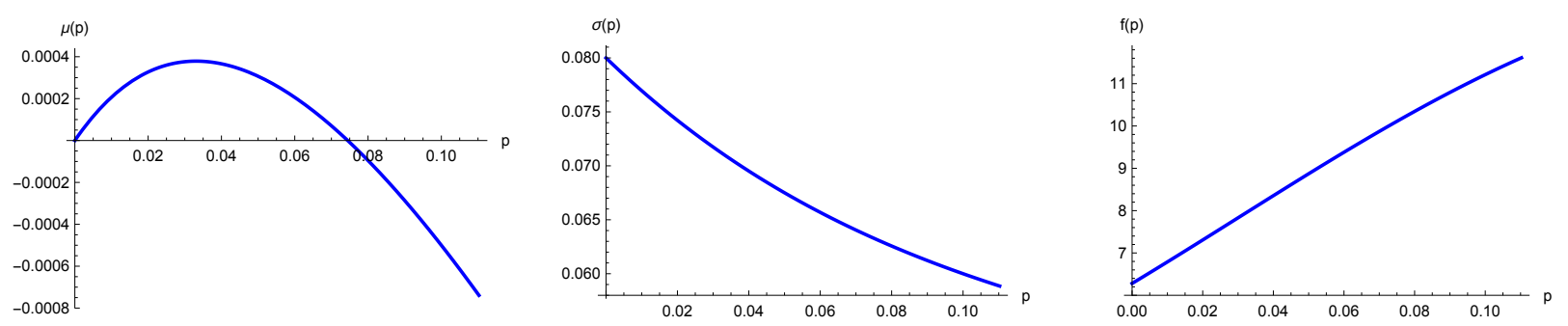

Notes: this figure depicts the typical patterns of the insurance price drift $\mu(p)$ (the right panel), insurance price volatility $\sigma(p)$ (the central panel) and the ergodic density of the insurance price $f(p)$ (the right panel) for $\alpha>\sqrt{2} r$ and $\beta>1$. Parameter values: $r=0.04, \sigma_{0}=0.05, \gamma=0.1, \alpha=0.5$ and $\beta=2$.

${ }^{10}$ See e.g., Ghosh (2010). 


\section{Conclusion}

This paper presents a general equilibrium version of the classical ruin theory model in continuous time, as studied for example by Gerber and Shiu (2004). We model a competitive insurance sector that offers insurance contracts to a population of potential insurees confronted with correlated risks. There is a unique competitive equilibrium in which prices and capacities are deterministic functions of the level of aggregate reserves in the insurance sector. The price dynamics can be computed explicitly. Rather than real cycles, insurance prices are characterized by asymmetric reversals. The market exhibits alternating periods where premium and profitability rise (hard markets) and fall (soft markets). The average duration of hard markets is shorter than that of soft markets, provided that the elasticity of the demand for insurance is not too low.

We also find that, even though the insurance premium is (weakly) predictable, there are no arbitrage opportunities. The reason is that investors cannot directly sell insurance contracts but can only buy and sell the stocks of insurance companies. The prices of these stocks are discounted martingales (in between dividend distributions and recapitalizations) but insurance premiums are not. Similarly, expected profits are positive, despite the perfect competition on the insurance market. This is because, in the presence of financial frictions and even when shareholders are risk neutral, insurance companies have to be compensated for their exposure to aggregate risks.

A natural extension of our model could allow for the analysis of the implications of regulatory measures, such as minimum reserve requirements. Another potential avenue of research would be to consider an alternative model specification with Poisson risk, which is better suited for modeling the catastrophe insurance market. Finally, a interesting line of inquiry would be to test the model prediction on the asymmetry of underwriting cycles. 


\section{References}

[1] Bloom, T.S., 1987. Cycles and Solutions. Best's Review: Property/Casualty Edition 86 (6), 2024.

[2] Bolton, P., Chen, H. and N. Wang, 2011. A Unified Theory of Tobin's q, Corporate Investment, Financing, and Risk Management. Journal of Finance 66, 1545 - 1578.

[3] Boyer, M., Jacquier E. and S. Van Norden, 2012. Are Underwriting Cycles Real and Forecastable? Journal of Risk and Insurance 79, 995 - 1015.

[4] Brunnermeier, M. K. and Y. Sannikov, 2014. A Macroeconomic Model with a Financial Sector. American Economic Review 104, 379 - 421.

[5] Cagle, J. and S. Harrington, 1995. Insurance Supply with Capacity Constraints and Endogenous Insolvency Risk. Journal of Risk and Uncertainty 11, 219 - 232.

[6] Chen, R., Wong, K. and H. Lee, 1999. Underwriting Cycles in Asia. Journal of Risk and Insurance $66,29-47$.

[7] Choi, S., Hardigree, D. and P. D. Thistle, 2002. The Property/Liability Insurance Cycle: A Comparison of Alternative Models. Southern Economic Journal 68, 530 - 548.

[8] Cummins, J. D. and F. Outreville, 1987. An International Analysis of Underwriting Cycles in Property-Liability Insurance. Journal of Risk and Insurance 54, 246 - 262.

[9] Doherty, N. A. and J. R. Garven, 1995. Insurance Cycles: Interest Rates and the Capacity Constraint Model. Journal of Business 68, 383 - 404.

[10] Froot, K. A. and P. G. J. O'Connell, 1997. On the Pricing of Intermediated Risks: Theory and Application to Catastrophe Reinsurance, NBER Working Paper 6043.

[11] Fung, H.-G., Lai, G., Patterson, G. A. and R. C. Witt, 1998. Underwriting Cycles in Property and Liability Insurance: An Empirical Analysis of Industry and By-Line Data. Journal of Risk and Insurance 65, 539 - 561.

[12] Gerber, H. U. and E. S. W. Shiu, 2004. Optimal Dividends: Analysis with Brownian Motion. North-American Actuarial Journal 8, 1 - 20.

[13] Ghosh, A. P., 2010. Backward and Forward Equations for Diffusion Processes. In Wiley Encyclopedia of Operations Research and Management Science (EORMS), edited by James J. Cochran, Louis A. Cox, Pinar Keskinocak, Jeffrey P. Kharoufeh and J. Cole Smith. Hoboken, NJ: Wiley.

[14] Gron, A., 1990. Property-Casualty Insurance Cycles, Capacity Constraints, and Empirical Results. Ph.D. dissertation, Department of Economics, Massachusetts Institute of Technology. 
[15] Gron, A., 1994. Capacity Constraints and Cycles in Property-Casualty Insurance Markets. RAND Journal of Economics 25, 110 - 127.

[16] Gron, A., and D. J. Lucas, 1998. External Financing and Insurance Cycles. In The Economics of Property-Casualty Insurance, edited by David F. Bradford, 5-27. Chicago: University of Chicago Press.

[17] Harrington, S.E., Niehaus, G. and Y., Tong, 2013. Insurance Price Volatility and Underwriting Cycles, in Georges Dionne, ed., Handbook of Insurance, Kluwer Academic, 2nd ed.

[18] Jeanblanc, M. and A. N. Shiryaev, 1995. Optimization of the flow of dividends. Russian Mathematical Surveys 50, $257-277$.

[19] Klimenko, N., Pfeil, S. and J.-C. Rochet, 2015. The Apples of Wrath: A Lucas Model with Extreme Financial Frictions. Working Paper, University of Zurich.

[20] Lai, G.C., Witt, R. C., Fung, H.-G., MacMinn R. D. and P. L. Brockett, 2000. Great (And Not so Great) Expectations: An Endogenous Economic Explication of Insurance Cycles and Liability Crises. Journal of Risk and Insurance 67, 617- 652.

[21] Lamm-Tennant, J. and M. A. Weiss, 1997. International Insurance Cycles: Rational Expectations/Institutional Intervention. Journal of Risk and Insurance 64, 415 - 439.

[22] Meier, U. B., 2006. Multi-National Underwriting Cycles in Property-Liability Insurance: Part 1 - some theory and empirical results. Journal of Risk Finance 7, 64 - 82.

[23] Meier, U. B. and J. F. Outreville, 2006. Business Cycles in Insurance and Reinsurance: the Case of France, Germany and Switzerland. Journal of Risk Finance 7, 160 - 176.

[24] Rochet, J.-Ch. and S. Villeneuve, 2011. Liquidity Management and Corporate Demand for Hedging and Insurance. Journal of Financial Intermediation 20, 303 - 323.

[25] Schmidli, H., 2008. Stochastic Control in Insurance. Springer, New York.

[26] Shreve, S. E., 2004. Stohastic Calculus for Finance II. Springer, New York.

[27] Stewart, B. D., 1984. Profit Cycles in Property-Liability Insurance. In J.D. Long, Ed., Issues in Insurance. American Institute for P/L Underwriters, Malvern.

[28] Venezian, E. C., 1985. Ratemaking Methods and Profit Cycles in Property and Liability Insurance. Journal of Risk and Insurance 52, 199 -221.

[29] Weiss, M. A., 2007. Underwriting Cycles: A Synthesis and Further Directions. Journal of Insurance Issues 30, 31 - 45 . 
[30] Weiss, M. A. and J.-H. Chung, 2004. U.S. Reinsurance Prices, Financial Quality, and Global Capacity. Journal of Risk and Insurance 71 (3), 437 - 467.

[31] Winter, R. A., 1988. The Liability Crisis and the Dynamics of Competitive Insurance Markets. Yale Journal on Regulation 5, 455 - 499.

[32] Winter, R. A., 1994. The Dynamics of Competitive Insurance Markets. Journal of Financial Intermediation 3, 379 - 415. 